\title{
Surface Roughness Evaluation of Different Polishing Techniques on Dental Porcelains By Atomic Force Microscopy
}

\author{
Goknil ERGUN KUNT DDS, $\mathrm{PhD}^{1}$, Işil SARIKAYA DDS, $\mathrm{PhD}^{2}$ \\ ${ }^{1}$ Associate Professor, Department of Prosthodontics, Faculty of Dentistry, University of Ondokuz Mayis, Samsun, Turkey \\ ${ }^{2}$ Assistant Professor, Department of Prosthodontics, Faculty of Dentistry, University of Gaziosmanpasa, Tokat, Turkey
}

*Corresponding author: Goknil Ergun Kunt DDS, PhD, Associate Professor in Department of Prosthodontics, Department of Prosthodontics, Faculty of Dentistry, Ondokuz Mayıs University, 55139, Atakum, Samsun, Turkey;Tel: 00903623121919-8234; Fax: 00903624576032; E-mail: gergun@omu.edu.tr

Received: December 06, 2018; Accepted: December 13, 2018; Published: December 17, 2018;

\begin{abstract}
Introduction: This study was conducted to find out different polishing techniques' effects on different porcelain materials by using atomic force microscopy (AFM).

Material and Methods: Samples were made from four different porcelain materials (VMK 95, Ceramco III, Matchmaker, Vitablocs Mark II). Nine groups $(n=5)$ were randomly formed from the samples of each ceramic and nine different polishing methods were applied on them. AFM was used to evaluate the external topography and roughness of dental porcelains. To analyze the results of the study ANOVA and Tukey test were used statistically (=0.05).

Results: Within the porcelain groups Ceramco and Matchmaker had higher Ra values, however VMK 95 and Mark II had lower Ra values. However when the different polishing techniques were compared, Gl (.1110) and SIPg (.2295) were found to have the lowest Ra values and no statistical differences were found between these two techniques ( $\mathrm{p}>$.05). In addition, no differences were found between glazed samples (Gl) and after polishing with Sof-lex and Prisma Gloss (Sl-Pg). On the other hand polishing with Sl and Pg together (Sl-Pg) significantly decreases the surface area.
\end{abstract}

Conclusions: There were statistically significance between the glazed and the other specimens. Different polishing methods influenced the surface topography of different porcelains significantly $(\mathrm{p}<.001)$.

Key words: AFM, surface roughness, polishing, dental porcelain

\section{Introduction}

The key factor of an esthetic fixed restorations is dental porcelains. Transparency, conveyance of light, and biocompatibility supply dental ceramics with exceptionally advantageous esthetic properties [1]. A smooth surface is important for the function, esthetic and biocompatibility of dental porcelains [2] and also it's preferable to decrease bacterial holding and to obtain a clear appearance [3]. The dental porcelain surface finishing procedure is achieved by glazing since their surfaces are smooth. In the delivery of porcelain fixed prosthesis, external alterations are crucial to improve occlusal obstructions and poor contours, to finalize the boundary of porcelains, and to enhance final look of restorations [4]. Generally, a smooth surface is essential because surface modifications of the porcelain damage glazing, thus creating rough, unpolished, nutrient-enhancing surfaces.

In this situation to refinish the porcelain surfaces intraorally with different polishing methods are mandatory to restablish surface smoothnes $[4,5]$. To create the surface smoothness of dental porcelains there are many different mechanical polishing methods using rotary instruments such as diamond bars and drills, different pastes, stones, rubber discs or different polishing kits.
Atomic force microscopy (AFM) is an important tool for qualitative and quantitative evaluation of surfaces which is presented in 1986 by Binning et al [6]. With the help of mechanical scanning, AFM directly inspects the exterior of the sample without using any lens or photon. With a sharp tip on, it scans over a surface, and measures the deflection, it is possible to get a topographic photograph of the surface. The deflection sensor may help to measure with enough sensitivity in disclose profiles with nanometer scale resolution [7]. With the contact, noncontact and tapping modes it's possible to have three different measurement records from different samples. AFM topographs give quantitive and structural (3D) information about surface of a material nanometrically which allows a high accuracy in finding out the external roughness. AFM can analyze the external roughness of dental porcelains [5, 8-11]. The null hypothesis in this research was that there are no differences between surface roughness of dental porcelains after different polishing methods by means of AFM evaluation.

\section{Material and Methods}

Four different commonly used dental porcelains (Vita VMK 95, Ceramco, Vitablocks Mark II and Matchmaker) and six different 
polishing systems glaze, finishing and polishing with polishing discs (Sof-Lex), polishing kit (Dialite II), polishing pastes (Sparkle, Zircate, Prisma Gloss) and combinations of them were investigated in this study (Table 1). One researcher prepared cylindrical samples $(15 \times 2 \mathrm{~mm})$ of four different dental porcelains by means of using polyvinylsiloxane mold to encapsulate the ceramics. All of the samples were mixed with a standart quantity of ceramic and liquid which were placed in the mold and condensed by using a plastic aparatus. A tissue (Selpak; Eczacıbaşı Holding, Sakarya, Turkey) was used to absorb excess moisture (Programat P80; Ivoclar Vivadent, Liechtenstein). The samples were taken away and putt into the oven in line with the producer's instructions (roughly $920-960^{\circ} \mathrm{C}$ ). The rectangular ceramic samples which were $12,14,18 \mathrm{~mm}$ in size were sliced into pieces of 2,14, $18 \mathrm{~mm}$ in size with a Buehler Isomet Low Speed cutting machine (Lake Bluff, Illinois, 60044-1699, USA). For a period of ten seconds, 600 grit silicon carbide paper was used by using a 300-rpm grinding MetaServ polishing (MetaServ, Buehler, England) to wetground ceramic discs. The samples were grouped in nine subgroups $(\mathrm{n}=5)$ and the following procedures were applied (Table 2):

Table 1. Materials used in the study.

\begin{tabular}{|c|c|c|}
\hline Material & Manufacturer & Material \\
\hline VMK 95 & Vita Zahnfabrik, Germany & Feldspathic porcelain \\
\hline Ceramco III & Degudent GmbH,USA & Feldspathic porcelain \\
\hline $\begin{array}{l}\text { Matchmaker } \\
\text { MC }\end{array}$ & Schottlander,UK & Low fusing porcelain \\
\hline $\begin{array}{l}\text { Vitablocks } \\
\text { Mark II }\end{array}$ & Vita Zahnfabrik, Germany & $\begin{array}{l}\text { Machinable feldspathic } \\
\text { porcelain }\end{array}$ \\
\hline Sof-Lex & 3M ESPE,USA & Finishing and polishing dics \\
\hline NTI Cera Glaze & NTI-Kahla GmbH,Germany & Porcelain polishing kit \\
\hline Dialite II & Brasseler,USA & Porcelain polishing kit \\
\hline Sparkle & Pulpdent,USA & Diamond polishing paste \\
\hline Zircate & Dentsply,USA & $\begin{array}{l}\text { Zirconium silicate clean- } \\
\text { ing-prophy paste }\end{array}$ \\
\hline Prisma Gloss & Dentsply,USA & $\begin{array}{l}\text { Aluminium oxide polishing } \\
\text { paste }\end{array}$ \\
\hline
\end{tabular}

Table 2. Different polishing groups.

\begin{tabular}{|c|c|}
\hline Study Groups & Polishing Techniques \\
\hline Group- Gl & Glaze \\
\hline Group- Sl & Sof- lex discs \\
\hline Group- Di & Dialite II polishing kit \\
\hline Group- Sp & Sparkle diamond polishing paste \\
\hline Group- Zr & Zircate polishing paste \\
\hline Group- Pg & Prisma Gloss polishing paste \\
\hline Group- SlSp & Sof- lex + Sparkle \\
\hline Group- SlZr & Sof- lex + Zircate \\
\hline Group- SlPg & Sof- lex + Prisma Gloss \\
\hline
\end{tabular}

Group Gl: with a predetermined glaze material, the samples were glazed.

Group Sl: the samples were polished with polishing discs of 12.7 mm diameter (Sof-Lex; 3M/ESPE, St. Paul, MN, USA) for ten seconds for fine and superfine discs at 30,000 rpm and for ten seconds for coarse and medium discs at 10,000 rpm by using an electric handpiece set by following the producer's directions.

Group Di: Dialite II ceramic polishing kit which had pre, fine and high-shine wheels was used to polish the samples for ten seconds at 10, $000 \mathrm{rpm}$.

Groups Sp: Sparkle diamond polishing paste was applied for ten seconds to the samples with a prophylaxis rubber cup (Kenda Polishers, Kenda AG, Liechtenstein) mounted on an electric handpiece at $15,000 \mathrm{rpm}$.

Groups Zr: Zircate zirconium silicate cleaning-prophy paste was applied as in the same method of Groups Sp above.

Groups Pg: Prisma Gloss aluminum oxide polishing paste was applied as in the same method of Groups Sp above.

Group SISp: The samples were polished first by following the procedure in Group Sl and then by following the procedure in Group Sp.

Group SIZr: First by following the procedure in Group Sl, the samples were polished and then by following the procedure in Group $\mathrm{Zr}$, zirconium silicate cleaning-prophy paste was applied.

Group SIPg: First polishing was done by following the procedure in Group Sl and then by following the procedure in group Pg aluminum oxide polishing paste was applied on the samples.

The same investigator performed all polishing procedures. Lastly, the specimens were cleaned ultrasonically for $10 \mathrm{~min}$ (Eurosonic Energy, Euronda, Italy) by using deionized water and then they were dried. Porcelain specimens were evaluated under an AFM (AFM, PSIA XE-100E, PSIA Inc, CA, USA) to obtain a quantitive and qualitative evaluation [5]. With a scan length of $20 \mu \mathrm{m} \times 20 \mu \mathrm{m}$ and a scan rate of $0.5 \mathrm{~Hz}$ [12]. AFM images were photographed (Figure 1a-4b). Following different external procedures, the average surface roughness $(\mathrm{Ra})$ of the ceramic substrate was examined by a single operator and analyzed after different surface treatments. Three measurements were performed from three different areas all located in the centre of the specimens $[13,14]$. Means and standart deviations of surface roughness measurements were determined. Two-way ANOVA was used to evaluate surface roughness data and SPSS (12.0.1; SPSS Inc, Chicago, IL, USA) was used for statistical analyses. Tukey was used to compare the mean values $(\mathrm{p}<0.05)$.

\section{Results}

The null hypothesis of the study was rejected. Statistically significant differences occured due to the various polishing methods on the external topography of different porcelains $(\mathrm{p}<.001)$. In the figures $(1 \mathrm{a}-4 \mathrm{~b})$ respectively three dimensional AFM images of different porcelain specimens subjected to different surface treatments are shown. There were statistically significance between the glazed and the other specimens $(\mathrm{p}<.05)$. On the other hand polishing with sof- 
lex and aluminum oxide polishing paste together (Sl-Pg) significantly decreases the surface area.

When the porcelain specimens are compared Mark II and VMK 95 were statistically different from Ceramco III and Matchmaker, and both of them presented similar result within as seen in (Table 3). When the polishing techniques are compared, group of Gl (.1110) and SIPg (.2295) were found to have the lowest Ra values and there were no statistically significant differences between the two groups (Table 4) $(\mathrm{p}>.05)$. The highest Ra value was obtained in the group of Sp $(.8511)(\mathrm{p}=.05)$.

Table 3. Mean surface roughness and differences between the groups of porcelains.

\begin{tabular}{|c|c|c|}
\hline Porcelains & Ra & Difference* $^{*}$ \\
\hline VMK 95 &, 3895 & A \\
\hline Mark II &, 3456 & A \\
\hline Ceramco &, 4907 & B \\
\hline Matchmaker &, 4967 & B \\
\hline
\end{tabular}

* Mean Ra values for groups in non homogeneous subsets are displayed with different letters $\mathrm{p}=.05$

Table 4. Mean surface roughness and differences between the groups of surface treatments.

\begin{tabular}{|c|c|c|}
\hline Surface Treatment & Ra & Difference* $^{*}$ \\
\hline Gl &, 1110 & $\mathrm{~A}$ \\
\hline SIPg &, 2295 & $\mathrm{Ab}$ \\
\hline SIZr &, 3507 & $\mathrm{Bc}$ \\
\hline Zr &, 4359 & $\mathrm{Cd}$ \\
\hline Pg &, 4384 & $\mathrm{Cd}$ \\
\hline Di &, 4609 & $\mathrm{Cd}$ \\
\hline SISp &, 4727 & $\mathrm{Cd}$ \\
\hline SI &, 5255 & $\mathrm{D}$ \\
\hline Sp &, 8511 & $\mathrm{E}$ \\
\hline $\begin{array}{l}\text { * Mean Ra values for groups in non homogeneous subsets are displayed with different } \\
\text { letters p= .05 }\end{array}$ &
\end{tabular}

When all the porcelains' surfaces were evaluated, the highest $\mathrm{Ra}$ value was in the group of Mark II Sp (1.147) (Figure 1a) and the lowest value was in Mark II Gl (0.0860) (Figure 1b) (Table 5). When the Ra value of VMK 95 porcelain evaluated the highest Ra was in the SISp (Figure 2a) and the lowest was in Gl group (Figure 2b). There weren't statistically significant differences between groups SlZr, Pg, SlPg, Zr, Sp and SISp for VMK 95 porcelain (Table 6). When the Ra value of Mark II porcelain evaluated the highest Ra was in the Sp (Figure 1a) and the lowest was in Gl group (Figure 1b). There weren't statistically significant differences between groups SlZr, Di, Pg, and Zr for Mark II porcelain (Table 5). When the Ra value of Matchmaker porcelain evaluated the highest Ra was in the Sl (Figure 3a) and the lowest was in Gl group (Figure $3 b$ ). No statistically significant differences were found between groups Gl, SlPg, SlZr and also the groups of Di, Pg, $\mathrm{Zr}$, Pg, Sl ve Sp for Matchmaker porcelain (Table 7). When the Ra value of Ceramco porcelain evaluated the highest $\mathrm{Ra}$ was in the $\mathrm{Sp}$
(Figure 4a) and the lowest was in SlPg group (Figure 4b). No statistically significant differences were found between groups SlZr, Di, Pg, Zr, Pg, SlSp, Sl for Ceramco porcelain (Table 8).

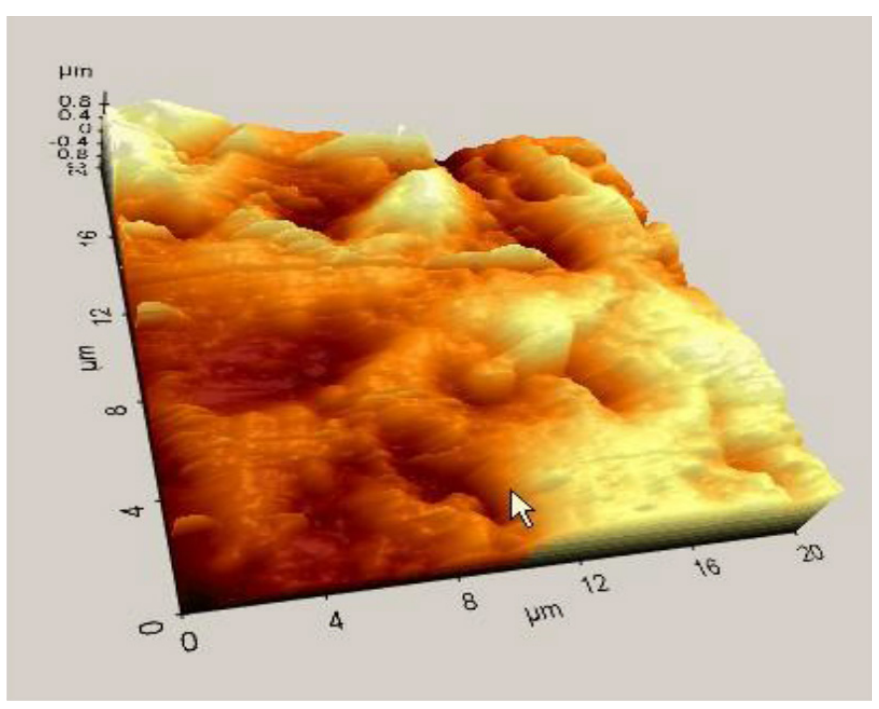

Figure 1a. Atomic force microscope image of Mark II Sp.

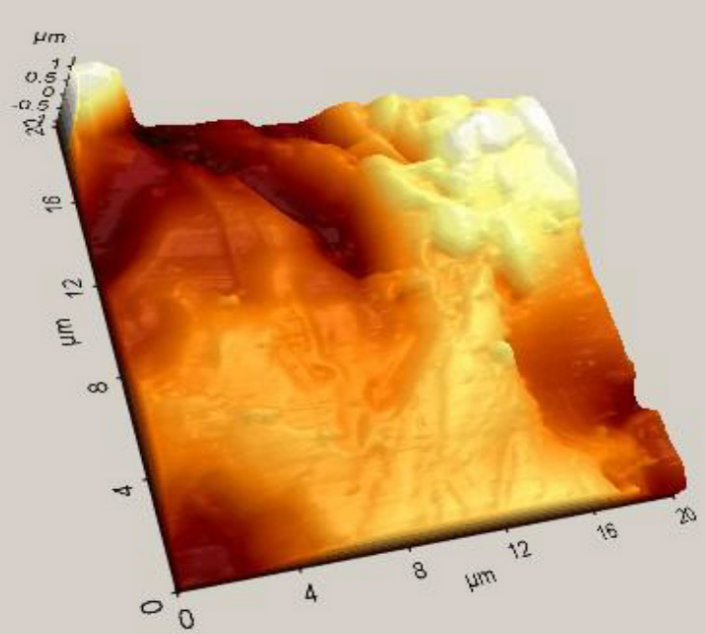

Figure 1b. Atomic force microscope image of Mark II Glaze.

Table 5. Mean surface roughness and differences for the Mark II porcelain subjected to different surface treatments.

\begin{tabular}{|c|c|c|}
\hline Surface Treatment & Ra & Difference * \\
\hline $\mathrm{Gl}$ &, 0860 & $\mathrm{~A}$ \\
\hline $\mathrm{SIPg}$ &, 2473 & $\mathrm{Ab}$ \\
\hline $\mathrm{SIZr}$ &, 3660 & $\mathrm{Bc}$ \\
\hline $\mathrm{Zr}$ &, 4293 & $\mathrm{Bcd}$ \\
\hline $\mathrm{Pg}$ &, 4510 & $\mathrm{Bcd}$ \\
\hline $\mathrm{Di}$ &, 4593 & $\mathrm{Cd}$ \\
\hline $\mathrm{SISp}$ &, 5973 & $\mathrm{Bcd}$ \\
\hline $\mathrm{SI}$ &, 6333 & $\mathrm{D}$ \\
\hline $\mathrm{Sp}$ & 1,147 & $\mathrm{E}$ \\
\hline \multicolumn{2}{|c|}{} \\
\hline $\begin{array}{l}\text { * Mean Ra values for groups in non homogeneous subsets are displayed with different } \\
\text { letters p=.05 }\end{array}$
\end{tabular}




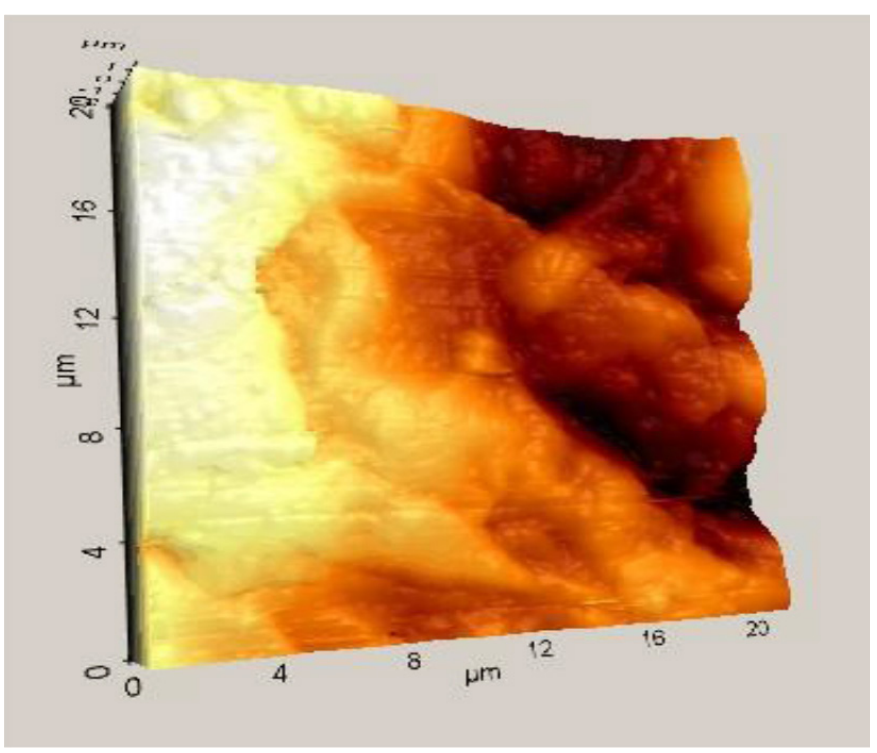

Figure 2a. Atomic force microscope image of VMK SISp.

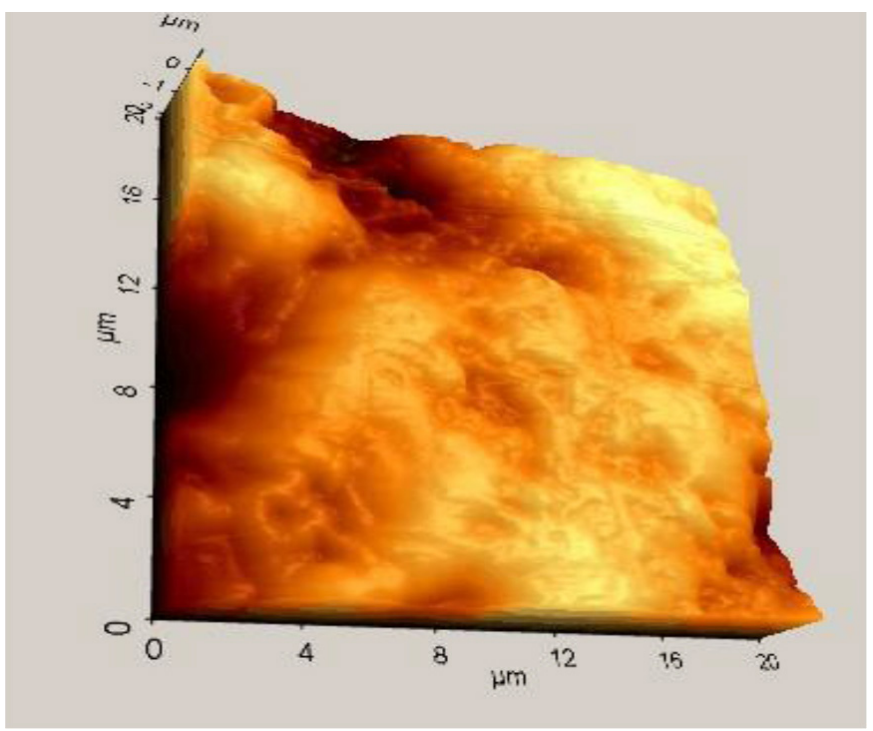

Figure 2b. Atomic force microscope image of VMK Glaze.

Table 6. Mean surface roughness and differences for the VMK 95 porcelain subjected to different surface treatments.

\begin{tabular}{|c|c|c|}
\hline Surface Treatment & Ra & Difference * \\
\hline $\mathrm{Gl}$ &, 1163 & $\mathrm{~A}$ \\
\hline $\mathrm{SIPg}$ &, 2960 & $\mathrm{Ab}$ \\
\hline $\mathrm{SIZr}$ &, 3303 & $\mathrm{Bc}$ \\
\hline $\mathrm{Zr}$ &, 3680 & $\mathrm{Cd}$ \\
\hline $\mathrm{Pg}$ &, 3703 & $\mathrm{Cd}$ \\
\hline $\mathrm{Di}$ &, 3830 & $\mathrm{Cd}$ \\
\hline $\mathrm{SISp}$ &, 4720 & $\mathrm{Cd}$ \\
\hline $\mathrm{SI}$ &, 4837 & $\mathrm{D}$ \\
\hline $\mathrm{Sp}$ &, 6860 & $\mathrm{E}$ \\
\hline
\end{tabular}

* Mean Ra values for groups in non homogeneous subsets are displayed with different letters $\mathrm{p}=.05$

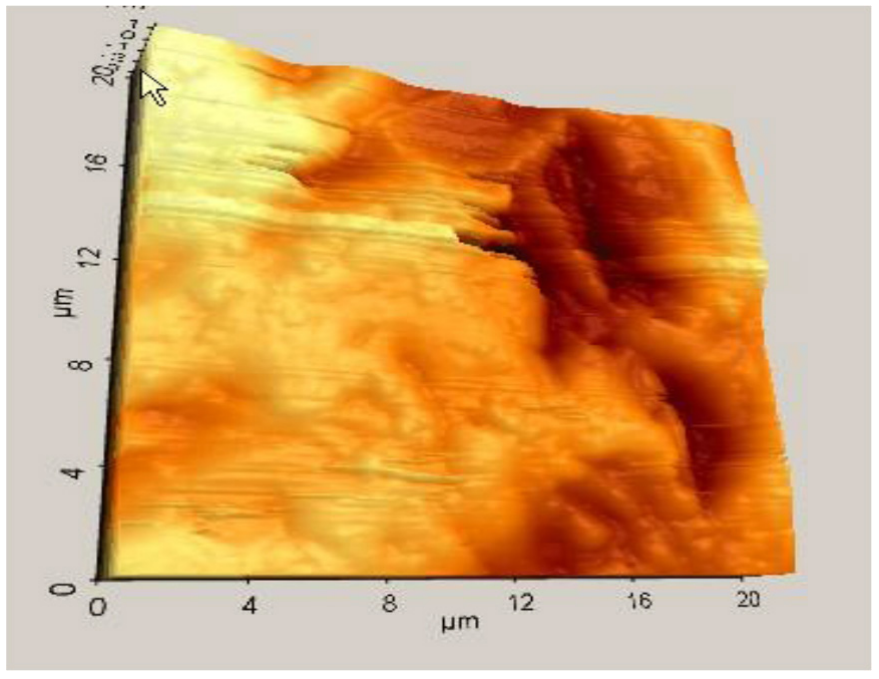

Figure 3a. Atomic force microscope image of Matchmaker Sl.

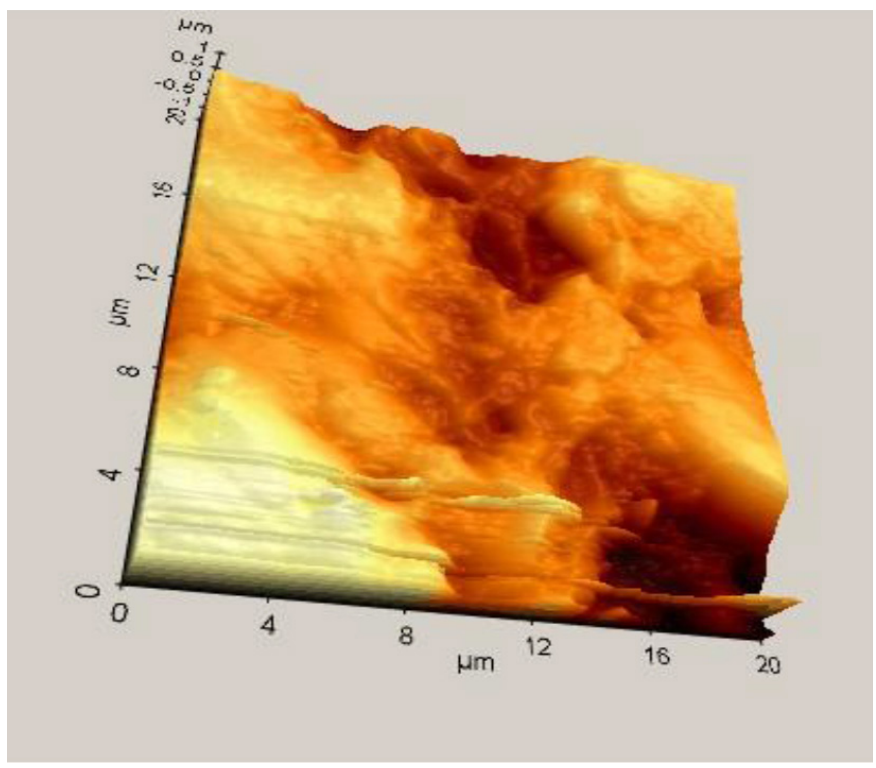

Figure 3b. Atomic force microscope image of Matchmaker Glaze.

Table 7. Mean surface roughness and differences for the Matchmaker MC porcelain subjected to different surface treatments.

\begin{tabular}{|c|c|c|}
\hline Surface Treatment & Ra & Difference* $^{*}$ \\
\hline Gl &, 1353 & A \\
\hline SIPg &, 1840 & $\mathrm{Ab}$ \\
\hline $\mathrm{SIZr}$ &, 3817 & $\mathrm{Abc}$ \\
\hline $\mathrm{Zr}$ &, 6187 & $\mathrm{Cde}$ \\
\hline $\mathrm{Pg}$ &, 5360 & $\mathrm{Cde}$ \\
\hline $\mathrm{Di}$ &, 6980 & $\mathrm{De}$ \\
\hline $\mathrm{SISp}$ &, 4540 & $\mathrm{Bcd}$ \\
\hline $\mathrm{SI}$ &, 7887 & $\mathrm{E}$ \\
\hline $\mathrm{Sp}$ &, 6740 & $\mathrm{Cde}$ \\
\hline $\mathrm{Ra}$
\end{tabular}

* Mean Ra values for groups in non homogeneous subsets are displayed with different letters $\mathrm{p}=.05$ 


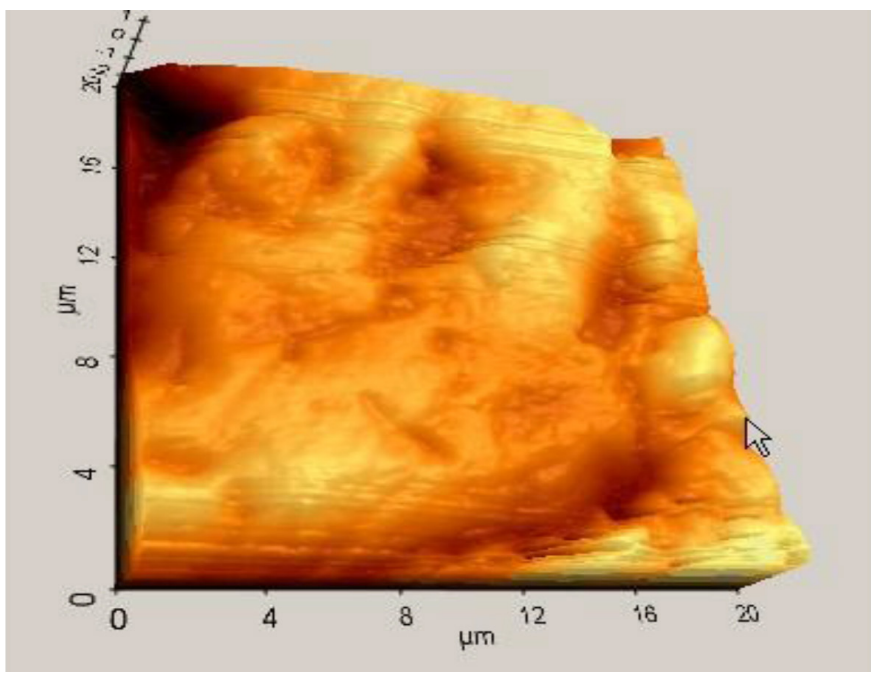

Figure 4a. Atomic force microscope image of Ceramco Sp.

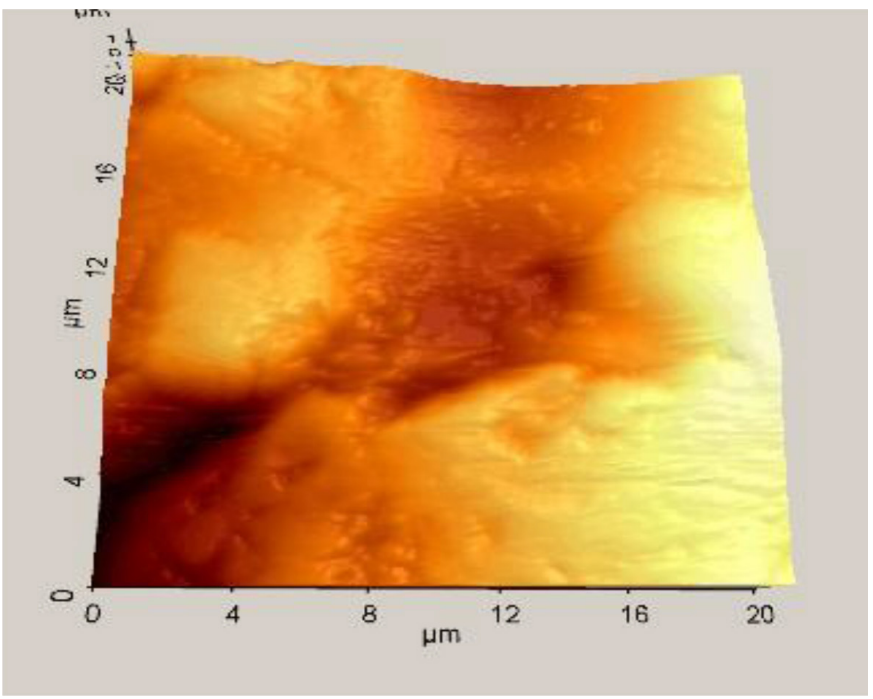

Figure 4b. Atomic force microscope image of Ceramco SIPg.

Table 8. Mean surface roughness and differences for the Ceramco porcelain subjected to different surface treatments.

\begin{tabular}{|c|c|c|}
\hline Surface Treatment & Ra & Difference * \\
\hline Gl &, 1063 & $\mathrm{a}$ \\
\hline SIPg &, 1037 & $\mathrm{a}$ \\
\hline SIZr &, 2870 & $\mathrm{ab}$ \\
\hline Zr &, 2020 & $\mathrm{ab}$ \\
\hline Pg &, 4180 & $\mathrm{~b}$ \\
\hline Di &, 2523 & $\mathrm{ab}$ \\
\hline SISp &, 2913 & $\mathrm{ab}$ \\
\hline SI &, 3497 & $\mathrm{ab}$ \\
\hline Sp & 1,100 & $\mathrm{c}$ \\
\hline * Mean Ra values for groups in non homogeneous subsets are displayed with \\
different letters p=.05
\end{tabular}

\section{Discussion}

The present study used AFM to examine the effect of various polishing techniques on four different conventional porcelain systems. Feldspathic VMK 95 and Mark II porcelain surfaces demonstrated significant lower Ra value than the other two porcelain systems after different polishing systems. The null hypothesis of the study was not accepted. There are several studies that report the effectiveness of porcelain polishing systems. Some authors report that there is no differences between the glaze and the polishing systems while others say that different polishing methods are not able to make a smooth surface as good as glazed [5, 15-24].

In the present study easy, useful and effective polishing systems were chosen. Sof-Lex is generally useful for the polishing of composites, and the manufacturer offers to use this system on the polishing of porcelains $[16,25]$. NTI, CeraGlaze and Dialite II are two different polishing kits which are cheaper than diamond pastes. They are easy to use intraorally. Sparkle is a diamond paste which is indicated to use on porcelains, composites, gold and other alloys.

Zircate, is a zirconium silicate polishing paste which is indicated for tooth polishing $[17,26]$. After periodontal threaphy polishing paste must not give damage to the restorative materials which are in the oral cavity. In this study we intend to observe the effect of zircate on porcelains. Prisma Gloss is an aluminium oxide polishing paste which is often used on composites $[18,27]$. It's also used in this study to observe its effectiveness on porcelains.

Flexural strength is affected by the material'surface roughness. Due to the decrease of the roughness of porcelain specimen surfaces, its flexural strength increases $[19,28]$.

The amount and the size of the abrasive fillers, and the shape of the polishing materials are the crictical issues for selection of the abrasive type for different contents of dental ceramics [18, 23]. It was observed that the surfaces of the ceramics were very rough and varied significantly for different polishing techniques and ceramic types. Vitablocs Mark II, which includes a glass matrix with nearly $30 \mathrm{vol} \%$ irregularlyshaped crystalline particles, is a modified feldspathic porcelain which is crystalline reinforced. It was stated by Yin et al [19] that surface finishing of Mark II which consisted of uniform and fine mica crystals was not succesful in decreasing surface roughness values. After mica crystals were cut with sharp $\mathrm{Al}_{2} \mathrm{O}_{3}$ abrasive particles, high peaks were left by Sof-lex disc. Leucite content of the dental ceramic seems to play an important role in surface roughness. Leucite porcelain involves fine leucite crystals which diffuse in glass matrix. Hence, when compared with porcelains with higher leucite content, lower leucite content were likely to show lower roughness after they were polished with rubber or disc followed by diamond pastes [18, 29]. In this study, lowest surface roughness was found in Glaze followed by Sof-Lex+Sparkle and SofLex+ Prisma Gloss. However Sparkle polishing paste presented the highest Ra value with a mean of 1.147 .

Different methods can be used to assess external roughness. In research on external roughness in dental materials, while qualitative methods such as SEM have been employed, quantitative methods 
such as surface profile analysis like profilometry and AFM have been employed. SEM has disadvantages in illustrating external topography, images allow only a two-dimensional view. In terms of both micron and nanometre scales, AFM has turned out to be a useful tool in examining material structure $[20,30]$. To obtain the three-dimensional view and to evaluate the surface topography of various ceramics at nanometre scale, the surfaces were surveyed using AFM. SEM analysis confirmed the results obtained with profilometer in several studies [5, $15,18,22,24]$.

In this study, polished ceramic types' usual three diameter surfaces which were atained by AFM imaging (Figure $1 \mathrm{~b}-4 \mathrm{~b}$ ) showed a rougher surface for unglazed sample which included higher crystallites with pointed peaks coming out of the surface perpendicularly. In addition, when compared with glazed ceramics, this type was found to have deeper cracks. Glaze seals are known to crack and pore within the ceramic material. Three digital imaging of the glazed sample (Figure 1a) shows that glaze has smoothed the sharp edges. RMS values, Ra values and $\mathrm{Z}$ range were shown to be significantly $(\mathrm{p}<0.01)$ higher in the unglazed samples as a result of statistical analysis.

In the study of Kakaboura et al [31], the surface characteristics of resin composites were illustrated through quantitative assessment of two-dimensional and three-dimensional profilometry and qualitative measurements by AFM and SEM. It was concluded that in distinguishing external roughness, AFM method was better when compared with two-dimensional profilometry and when compared with SEM, it defined external texture in more detail. Before this study Sarikaya and Guler [29] were evaluated surface roughness of the same materials subjected to the same polishing methods by profilometry. When we compared the results of the two study it's obviously seen that AFM apperared to offer a powerful tool to directly evaluate the roughness of porcelain specimens. The differences between the two study may be due to the method of the surface roughness evaluation. In the results of their study it was seen that feldspathic ceramics (Mark II) had lower Ra values when compared with the others. In this study Mark II has lower Ra value $(0,3456)$ than feldspathic porcelain (VMK95) $(0,3895)$ but there wasn't statistically differences between two materials. Also there were significantly differences among the polishing techniques for the Ra values of Mark II porcelain. Why the differences between the results of two study may be the effect of evaluation method of surface roughness measurements (profilometry and AFM).

Some authors have even recommended such polishing techniques as alternatives to glazing [15-24, 29, 32-34] but they concluded that it will be the object of further study. Also further studies are need with different composition of the particles and matrix substance, shape of the particles of abrasive ceramic polishing discs and wheels.

\section{Conclusion}

1. The surface roughness of the glazed ceramic material was lower than of the other polishing treatments.

2. The crystallites of the unglazed ceramic surfaces has higher and the pores were deeper compared to the glazed samples.
3. Sof-Lex+Sparkle and Sof-Lex+ Prisma Gloss polishing techniques may be alternatives to glazing.

4. AFM is a powerfull tool for the evaluation of surface roughness.

\section{Conflicts of Interest}

The authors declare that there is no potential conflicts of interest with respect to the authorship or publication of this article.

\section{Funding Statement}

This work is supported in part by Ondokuz Mayis University, PYO.DIS.1901.09.003

\section{References}

1. Shillingburg HT, Hobo S, Whitsett LD, Jacobi R, Brackett SE (1997) Fundamentals of Fixed Prosthodontics. (3rdedn). Quintessence Publishing Co, Inc, Canada Pg No: 433-436.

2. Yilmaz K, Ozkan P(2010) The methods for the generation of smoothness in dental ceramics. Compend Contin Educ Dent 31: 30-32, 34, 36-8 passim. [crossref]

3. Craig RG, Powers JM, Wataha JC (2004) Properties and Manipulation. (8th edn). Mosby; Dent. Mat, China Pg No: 113.

4. al-Wahadni A, Martin DM (1998) Glazing and finishing dental porcelain: a literature review. J Can Dent Assoc 64: 580-583. [crossref]

5. Tholt de Vasconcellos B, Miranda-Júnior WG, Prioli R, Thompson J, Oda M (2006) Surface roughness in ceramics with different finishing techniques using atomic force microscope and profilometer. Oper Dent 31: 442-449. [crossref]

6. Binnig G, Quate CF, Gerber C (1986) Atomic force microscope. Phys Rev Lett 56: 930-933. [crossref]

7. Miller JD, Veeramasuneni S, Drelich J, Yalamanchili MR, Yamauchi G (1996) Effect of roughness as determined by atomic force microscopy on the wetting properties of PTFE thin films. Poly Eng Sci 36: 1849-1855.

8. Botta AC, Duarte S Jr, Paulin Filho PI, Gheno SM (2008) Effect of dental finishing instruments on the surface roughness of composite resins as elucidated by atomic force microscopy. Microsc Microanal 14: 380-386. [crossref]

9. Casucci A, Osorio E, Osorio R, Monticelli F, Toledano M, et al. (2009) Influence of different surface treatments on surface zirconia frameworks. J Dent 37: 891-897. [crossref]

10. de Oyagüe RC, Monticelli F, Toledano M, Osorio E, Ferrari M, et al. (2009) Influence of surface treatments and resin cement selection on bonding to denselysintered zirconium-oxide ceramic. Dent Mater 25: 172-179. [crossref]

11. Clelland NL, Agarwala V, Knobloch LA, Seghi RR (2001) Wear of enamel opposing low-fusing and conventional ceramic restorative materials. J Prosthodont 10: 8-15. [crossref]

12. Casucci A, Mazzitelli C, Monticelli F, Toledano M, Osorio R, et al. (2010) Morphological analysis of three zirconium oxide ceramics: Effect of surface treatments. Dent Mater 26: 751-760. [crossref]

13. Fuzzi M, Zaccheroni Z, Vallania G (1996) Scanning electron microscopy and profilometer evaluation of glazed and polished dental porcelain. Int J Prosthodont 9: 452-458. [crossref]

14. Martínez-Gomis J, Bizar J, Anglada JM, Samsó J, Peraire M (2003) Comparative evaluation of four finishing systems on one ceramic surface. Int J Prosthodont 16 : 74-77. [crossref]

15. Goldstein GR, Barnhard BR, Penugonda B (1991) Profilometer, SEM, and visual assessment of porcelain polishing methods. J Prosthet Dent 65: 627-634. [crossref]

16. Wright MD, Masri R, Driscoll CF, Romberg E, Thompson GA, et al. (2004) Comparison of three systems for the polishing of an ultra-low fusing dental porcelain. J Prosthet Dent 92: 486-490. [crossref]

17. Sarac D, Sarac YS, Yuzbasioglu E, Bal S (2006) The effects of porcelain polishing systems on the color and the surface texture of feldspathic porcelain. $J$ Prosthet Dent 96: 122-128. [crossref]

18. Sasahara RM, Ribeiro Fda C, Cesar PF, Yoshimura HN (2006) Influence of the finishing technique on surface roughness of dental porcelains of different microstructures. Oper Dent 31: 577-583. [crossref]

19. Ling Yin, Song XF, Song YL, Huang T, Li J (2006) An overview of in-vitro abrasive finishing \& $\mathrm{CAD} / \mathrm{CAM}$ of bioceramics in restorative dentistry. Int J Machine Tools Manu 46: 1013-1026.

20. Karan S, Toroglu MS (2008) Porcelain refinishing with two different polishing systems after orthodontic debonding. Angle Orthod 78: 947-953. [crossref] 
21. Flury S, Lussi A, Zimmerli B (2010) Performance of different polishing techniques for direct CAD/CAM ceramic restorations. Oper Dent 35: 470-481. [crossref]

22. Anmol C, Soni S (2014) Effect of two different finishing systems on surface roughness of feldspathic and flourapatite porcelains in ceramo-metal restorations: Comparative in vitro study. J Int Soc Prevent Communit Dent 4: 22-28. [crossref]

23. Han GJ, Kim JH, Lee MA, Chae SY, Lee YH, et al. (2014) Performance of a novel polishing rubber wheel in improving surface roughness of feldspathic porcelain. Dent Mater J 33: 739-748. [crossref]

24. Manjuran NG, Sreelal T (2014) An in-vitro study to identify a ceramic polishing protocol effecting smoothness superior to glazed surface. J Indian Prosthodont Soc 4: 219-227. [crossref]

25. 3M ESPE Dental Products Instructions for Use (2004) 3M ESPE AG, Germany.

26. Zircate Material Safety Data Sheet (2003) Dentsply Int. Inc., USA.

27. Roulet JF, Roulet-Mehrens TK (1982) The surface roughness of restorative materials and dental tissues after polishing with prophylaxis and polishing pastes. $J$ Periodontol 53: 257-266. [crossref]

28. Terry DA, Geller W, Tric O, Anderson MJ, Tourville M, et al. (2002) Anatomical form defines color: Function, form and aesthetics. Pract Proced Aesthet Dent 14: 59-67. [crossref]
29. Sarikaya I, Güler AU (2010) Effects of different polishing techniques on the surface roughness of dental porcelains. J Appl Oral Sci 18: 10-16. [crossref]

30. Jagger DC, Harrison A (1994) An in vitro investigation into the wear effects of unglazed, glazed, and polished porcelain on human enamel. J Prosthet Dent 72 : 320-323. [crossref]

31. Kakaboura A, Fragouli M, Rahiotis C, Silikas N (2007) Evaluation of surface characteristics of dental composites using profilometry, scanning electron, atomic force microscopy and gloss-meter. J Mater Sci Mater Med 18: 155-163. [crossref]

32. Camacho GB, Vinha D, Panzeri H, Nonaka T, Gonçalves M (2006) Surface roughness of a dental ceramic after polishing with different vehicles and diamond pastes. Braz Dent J 17: 191-194. [crossref]

33. Yuzugullu B, Celik C, Erkut S, Ozcelik TB (2009)The effects of extraoral porcelain polishing sequences on surface roughness and color of feldspathic porcelain. Int $J$ Prosthodont 22: 472-475. [crossref]

34. Mehulić K, Svetlicić V, Segota S, Vojvodić D, Kovacić I, et al. (2010) A study of the surface topography and roughness of glazed and unglazed feldspathic ceramics. Coll Antropol 34: 235-238. [crossref]

\section{Citation:}

Goknil Ergun Kunt (2018) Surface Roughness Evaluation of Different Polishing Techniques on Dental Porcelains By Atomic Force Microscopy. J Dent Maxillofacial Res Volume 1(2): 1-7. 